\title{
Apolipoprotein E gene polymorphism and risk of type 2 diabetes and cardiovascular disease
}

\author{
Dalia El-Lebedy ${ }^{1 *}$, Hala M. Raslan² and Asmaa M. Mohammed ${ }^{3}$
}

\begin{abstract}
Background: Lipoprotein-related mechanisms have been associated with damage to the cardiovascular system in diabetic patients. Apolipoprotein E gene which affects the clearance of lipoproteins and consequently the lipid profile in our body is one of the most studied candidate genes and recently has been reported to be associated with T2DM and CAD. In this work, we studied the association of apoE gene polymorphism with T2DM and CVD and its effect on plasma lipids profile.

Methods: Our study was conducted on 284 subjects categorized into 100 patients with T2DM, 100 patients with T2DM complicated with CVD and 84 normal control subjects. ApoE gene polymorphism was genotyped by real-time PCR using TaqMan ${ }^{\circledR}$ SNP Genotyping Assay.

Results: ApoE E3/E3 genotype was the most common in our subjects. The frequencies of E3/E4 genotype and $\varepsilon 4$ allele were increased in both T2DM patients and CVD patients as compared with controls, but were significant only in CVD patients ( $p=0.004$ and 0.007 , respectively). Diabetic patients who carried E3/E4 genotype were at 2.4-fold increased risk to develop CVD $(95 \% \mathrm{Cl} 1.14-5.19, \mathrm{P}=0.02)$ and the $\varepsilon 4$ allele associated with 2.23-fold higher CVD risk (95\% Cl 1.09-4.59, $\mathrm{P}=0.02$ ). After adjustment for other established risk factors, E3/E4 genotype was an independent risk factor for $C V D(O R=2.3, p=0.009)$ but not for $T 2 D M(O R=1.7, p=0.28)$, while $\varepsilon 4$ allele was an independent risk factor for both T2DM $(O R=2.2, p=0.04)$ and CVD $(O R=3.0, p=0.018)$ with 5.9-fold increased risk to develop CVD in T2DM patients ( $p=0.019)$. E3/E4 genotype associated with significantly higher levels of TC and non HDL-C in all groups and with significantly higher levels of LDL-C in both T2DM and CVD patients.
\end{abstract}

Conclusions: ApoE gene polymorphisms associate with CVD and affect the lipid profile. The $\varepsilon 4$ allele is an independent risk factor for both T2DM and CVD. Further genetic studies to add information beyond the traditional cardiovascular risk factors in T2DM and to identify risk genotypes will help in early prediction and identification of at risk patients.

Keywords: Apolipoprotein E, Polymorphism, Type 2 diabetes mellitus, Cardiovascular disease

\section{Background}

Type 2 diabetes mellitus (T2DM) is one of the most common diseases with a high incidence and prevalence throughout the world [1]. The prevalence of type 2 diabetes is rising at an alarming rate due to increase in life expectancy, obesity, physical inactivity and adoption of

\footnotetext{
*Correspondence: d_lebedy@yahoo.co.uk

${ }^{1}$ Medical Research Division, Department of Clinical and Chemical Pathology, National Research Centre, Al-Bohouth Street, Cairo 12311, Egypt

Full list of author information is available at the end of the article
}

sedentary lifestyles [2]. In 2013, the International Diabetes Federation (IDF) estimated that almost 366 million people $(8.3 \%$ of the adult population) around the world have diabetes, and 280 million people $(6.4 \%$ of the adult population) have impaired glucose tolerance (IGT), a major risk factor for type 2 diabetes. By 2030, these figures are expected to rise to 552 million $(9.9 \%$ of the world's population) and 398 million (7.1\% of the adult population), respectively. In developing countries, the number of people with diabetes will increase by $150 \%$ in the next 25 years [3]. Egypt is in the world $8^{\text {th }}$ place in 
terms of diabetes incidence, affecting up to $9.3 \%$ of population, and due to a rapidly increasing and ageing population, Egypt will have the highest projected number of people with diabetes in the region by 2025 [3].

T2DM is a major independent risk factor for cardiovascular disease (CVD), the most common cause of morbidity and mortality among diabetic patients [4]. The increasing incidence of non-communicable diseases (NCDs) including diabetes and cardiovascular diseases, places a huge burden on Egypt's healthcare resources and about $41 \%$ of all deaths in Egypt are from NCDs [5]. Therefore, better understanding of the pathogenesis of CVD and T2DM is of great interest for early prediction and identification of at-risk patients and for better clinical management.

Modifiable factors such as dyslipidemia, obesity, oxidative stress, smoking, exercise and alcohol intake, as well as non-modifiable factors: age, sex, positive family history and genetic predisposition of the individual, have been identified as risk factors for both T2DM and CVD [6].

Lipoprotein- related mechanisms have been associated with damage to the cardiovascular system in diabetic patients [7]. Apolipoprotein E (ApoE) gene which affects the clearance of lipoproteins [8] and, consequently, the lipid profile in our body [9] is one of the most studied candidate genes for T2DM and/or CVD in the last decade.

ApoE gene, located on the long arm of chromosome 19 at position q13.2, is a polymorphic gene with single nucleotide polymorphisms (SNPs) at positions 112 and 158 resulting in three major alleles: $\varepsilon 2$, $\varepsilon 3$, and $\varepsilon 4$, coding for 3 isoforms: apoE2 (Cys112/Cys158), the most common apoE3 (Cys112/Arg158) and apoE4 (Arg112/ Arg158) with 6 possible genotypes: E2/E2, E2/E3, E3/E3, E3/E4, E4/E4 and E2/E4 [6, 10].

ApoE isoforms have different effects on the metabolism of lipoproteins. Allele $\varepsilon 2$ is associated with lower plasma levels of LDL cholesterol and lower risk of coronary artery disease (CAD) [11], meanwhile, $\varepsilon 4$ allele is associated with higher plasma levels of total cholesterol (TC), LDL-C, very low-density lipoprotein cholesterol (VLDL$\mathrm{C}$ ), and greater risk of CAD when compared with $\varepsilon 3$ allele [12]. Impaired lipid clearance by apoE $\varepsilon 4$ is attributed to its higher affinity to LDL-R compared to other alleles leading to early "receptor occupation" and accumulation of LDL particles which suppress LDL-R synthesis resulting in lower clearance of lipoproteins from the body through LDL-R [13]. Also, a direct relationship between apoE isoforms and premature atherosclerosis has been reported [6] and recently apoE $\varepsilon 4$ allele has been associated with the development of both T2DM and CAD [14]. The aim of this study is to investigate the association of
apoE gene polymorphism with T2DM and CVD and its effect on plasma lipid levels.

\section{Methods}

\section{Subjects}

Studied subjects were recruited from the Outpatients Clinic of the National Research Centre and the National Diabetes and Endocrinology Institute. Data of family and medical history, smoking habits and physical activity was obtained by questionnaire. Physical activity was defined as exercise for 2-3 days/week for at least $30 \mathrm{~min}$. Clinical examination including measurement of systolic blood pressure (SBP) and diastolic blood pressure (DBP) was applied. Anthropometric measurements (weight and height) were collected and used for BMI calculation according to the standard formula BMI = weight $(\mathrm{kg}) /$ [height $(\mathrm{m})]^{2}$. Hypertension was defined as blood pressure above $140 / 90 \mathrm{mmHg}$ or taking antihypertensive drugs. Dyslipidemia was defined as level of total cholesterol (TC) $>200 \mathrm{mg} / \mathrm{dL}$, triglycerides $(\mathrm{TG})>150 \mathrm{mg} /$ $\mathrm{dL}, \mathrm{LDL}-\mathrm{C}>130 \mathrm{mg} / \mathrm{dL}, \mathrm{HDL}-\mathrm{C}<40 \mathrm{mg} / \mathrm{dL}, \mathrm{TC} / \mathrm{HDL}-\mathrm{C}$ ratio $>4.0$ or under medication of lipid lowering drugs [15]. According to the criteria of American Diabetes Association [16], studied subjects were classified into 3 groups:

Control group included 84 healthy subjects with fasting plasma glucose (FPG) $<100 \mathrm{mg} / \mathrm{dL}$. Exclusion criteria were hyperlipidemia, hypertension, CVD or family history of any form of CVD, diabetes mellitus, hepatic and renal diseases, endocrine disease, metabolic disorders, autoimmune diseases and those under medication.

T2DM patients without CVD included 100 subjects fulfilled the diabetes mellitus diagnostic criteria of FPG $\geq 126 \mathrm{mg} / \mathrm{dL}$ or under diabetes medication (oral and/ or insulin) with no history or signs of any CVD. Exclusion criteria included renal disease, hepatic disease, endocrine disease, metabolic disorders and autoimmune diseases.

T2DM complicated with CVD included 100 subjects diagnosed to have diabetes with FPG $\geq 126 \mathrm{mg} / \mathrm{dL}$ or under diabetes medication and complicated with any of the vascular disease e.g. ischemic heart disease (IHD), macroangiopathy and/or cerebrovascular disease. Exclusion criteria included renal disease, hepatic disease, endocrine disease, metabolic disorders and autoimmune diseases.

Informed consent was obtained from all subjects and the study protocol was approved by the Ethics Committee of the National Research Centre.

\section{Lipid analysis and biochemical markers}

Venous blood samples were collected from all subjects after $12 \mathrm{~h}$ fast. Total cholesterol (TC), Triglycerides (TG), 
high density lipoprotein cholestrol (HDL-C), low density lipoprotein cholestrol (LDL-C), fasting plasma glucose (FPG) were assayed on Roche Diagnostics clinical chemistry auto analyzer c311 (Germany). Glycosylated hemoglobin (HbA1c) was measured by high-performance liquid chromatographic (HPLC) method using Agilent 1100 series HPLC system (Agilent Technologies, Germany). VLDL-C level was calculated using the following equation: VLDL-C $=(\mathrm{TC}-\mathrm{LDL}-\mathrm{C}-\mathrm{HDL}-\mathrm{C})$. NonHDL-C level was calculated by subtracting HDL-C value from TC value [17].

\section{ApoE genotyping}

Genomic DNA was extracted from $2 \mathrm{ml}$ of whole peripheral blood using QIAamp DNA extraction kit (Qiagen Hilden, Germany, Cat no. 51304) according to the manufacturer's protocol.

ApoE gene was genotyped using TaqMan ${ }^{\circledR}$ SNP Genotyping Assays. SNPs at positions 112 (rs429358) and 158 (rs7412) determined the encoded alleles, $\varepsilon 2$ (rs429358$\mathrm{T}+\mathrm{rs} 7412-\mathrm{T}), \varepsilon 4(\mathrm{rs} 429358-\mathrm{C}+\mathrm{rs} 7412-\mathrm{C})$ and $\varepsilon 3$ allele (rs429358-T + rs7412-C). All primers and probes were designed by Applied Biosystems (Foster City, CA, USA) and genotyping analyses were performed on ABI 7500 Real Time PCR system (Applied Biosystems) according to the manufacturer's protocol. For genotyping quality control, negative controls were included in all SNPs and $10 \%$ of samples were randomly selected and analyzed in duplicates and the concordance rate was $100 \%$.

\section{Statistical analysis}

The collected data and the clinical results have been statistically analyzed using IBM SPSS version 20.0 software (Statistical Package for Social Science). Quantitative data were expressed as mean values \pm standard deviation (SD). Ranges and frequency of distributions were estimated for quantitative variables. Normally distributed data were compared using Student's $t$ test for 2 groups and ANOVA test for more than 2 groups. The significance of differences between proportions was tested by the Chi square test $\left(\chi^{2}\right)$. Differences were considered significant with $\mathrm{p}$ value $<0.05$. Allele and genotype differences between groups and deviations from HardyWeinberg equilibrium were tested by Chi square test. Univariable logistic regression analysis was used to test the association between diseases and Apo E gene polymorphism and presented as unadjusted odds ratios (OR) with confidence interval $(95 \% \mathrm{CI})$. Multivariate logistic regression analysis was used to determine the risk factors for development of diseases with adjustment for potential covariates: age, gender, BMI, smoking status and physical activity and presented as adjusted ORs.

\section{Results}

General characteristics and biochemical variables of the study population

The study included 284 subjects classified into 100 patients with T2DM, 100 patients with T2DM + CVD, and 84 control subjects. Their age ranged from 40 to 68 years. The frequencies of CVDs in our patients were: $67 \%$ ischemic heart disease (IHD), $13 \%$ cerebrovascular disease, $11 \%$ macroangiopathy, $6 \%$ combined IHD and cerebrovascular disease, and $3 \%$ combined macroangiopathy and cerebrovascular disease.

A significant age difference was found between control subjects and CVD patients $(\mathrm{p}<0.0001)$ implying a higher risk of developing CVD with increasing age. Also a significant sex difference was found between CVD patients and, both, controls $(\mathrm{p}=0.003)$ and T2DM patients $(\mathrm{p}=0.01)$, signifying that male gender is associated with higher chances to develop CVD and T2DM. Diabetic patients with CVD had lower levels of physical activity $(p=0.005)$ and longer durations of diabetes $(p=0.001)$ when compared to controls and T2DM patients. BMI, SBP and DBP were significantly higher in patient groups than in controls. Higher frequencies of hypertension $(\mathrm{p}<0.0001)$ and smoking $(\mathrm{p}=0.01)$ were observed among CVD patients when compared to T2DM patients. Plasma glucose and $\mathrm{HbA} 1 \mathrm{C}$ levels were significantly higher in patients compared to controls ( $p<0.0001$ ).

Lipid profile data showed a significant association between dyslipidemia and CVD in diabetic patients ( $p<0.0001)$. Significantly higher levels of TC, TG, LDLC, VLDL-C, non HDL-C, TC/HDL-C and lower levels of HDL-C were demonstrated in patients compared to controls. CVD patients showed significantly lower levels of HDL-C ( $p=0.018)$ and higher levels of TC $(\mathrm{p}=0.027)$, VLDL-C ( $\mathrm{p}=0.015)$, non HDL-C $(\mathrm{p}=0.009)$ than T2DM patients. Demographic, clinical and biochemical data of enrolled subjects are summarized in Table 1.

\section{ApoE genotype and allele frequencies in patients and controls}

The genotype distributions of all groups were in HardyWeinberg equilibrium ( $p>0.05)$. E3/E3 was the most common genotype in our subjects. Genotype and allele frequencies among studied groups showed significant differences ( $\mathrm{p}=0.014$ and 0.023 , respectively). In CVD patients, the frequency of E3/E3 genotype was significantly lower $(\mathrm{p}=0.04)$, while the frequencies of E3/E4 genotype and $\varepsilon 4$ allele were significantly higher when compared to controls ( $\mathrm{p}=0.004$ and 0.007 , respectively). In T2DM patients, though E3/E4 genotype and $\varepsilon 4$ allele frequencies were higher than in controls, the differences were not significant ( $\mathrm{p}=0.41$ and 0.43 , respectively) (Fig. 1). 
Table 1 Demographic, clinical and biochemical data of the study population

\begin{tabular}{|c|c|c|c|}
\hline Variable & $\begin{array}{l}\text { Controls } \\
(n=84)\end{array}$ & $\begin{array}{l}\text { T2DM } \\
(n=100)\end{array}$ & $\begin{array}{l}\text { T2DM + CVD } \\
(n=100)\end{array}$ \\
\hline Age (years) & $51.8 \pm 5.2$ & $50.9 \pm 7.5$ & $58.3 \pm 7.2^{* *}$ \\
\hline Sex (male/female) & $45 / 39$ & $57 / 43$ & $74 / 26^{* * \dagger}$ \\
\hline $\mathrm{BMI}\left(\mathrm{kg} / \mathrm{m}^{2}\right)$ & $23.21 \pm 4.62$ & $27.59 \pm 4.90^{*}$ & $29.81 \pm 5.55^{* *}$ \\
\hline SBP $(m m H g)$ & $115.3 \pm 9.6$ & $131.5 \pm 19.7^{*}$ & $145.1 \pm 22.6^{* *}+$ \\
\hline $\mathrm{DBP}(\mathrm{mmHg})$ & $77.6 \pm 6.9$ & $79.7 \pm 18.0^{*}$ & $90.6 \pm 9.7^{* *} \dagger$ \\
\hline Hypertension (\%) & - & 31.4 & $94.7^{\dagger}$ \\
\hline Smokers (\%) & 11.1 & 7.8 & $15.7^{\dagger}$ \\
\hline Physical activity (\%) & 66.7 & 54.9 & $31.6^{* * \dagger}$ \\
\hline Diabetes duration (years) & - & $8.4 \pm 7.2$ & $13.3 \pm 7.4^{\dagger}$ \\
\hline Dyslipidemia (\%) & - & 72.5 & $92.1^{\dagger}$ \\
\hline Glucose (mg/dL) & $85 \pm 9.5$ & $147.1 \pm 64.1^{*}$ & $161 \pm 66.2^{* *}$ \\
\hline HbA1c (\%) & $5.3 \pm 0.6$ & $6.4 \pm 1.2^{*}$ & $6.6 \pm 1.3^{* *}$ \\
\hline Triglyceride (mg/dL) & $118.3 \pm 31.1$ & $145.6 \pm 72^{*}$ & $164.5 \pm 66.2^{* *}$ \\
\hline $\mathrm{TC}(\mathrm{mg} / \mathrm{dL})$ & $175.7 \pm 16$ & $192.1 \pm 48.4^{*}$ & $212.7 \pm 47.9^{* * \dagger}$ \\
\hline $\mathrm{LDL}-\mathrm{C}(\mathrm{mg} / \mathrm{dL})$ & $104.7 \pm 7$ & $118.22 \pm 38.9^{*}$ & $123 \pm 43.7^{* *}$ \\
\hline $\mathrm{HDL}-\mathrm{C}(\mathrm{mg} / \mathrm{dL})$ & $53.9 \pm 9.7$ & $49.2 \pm 11.2^{*}$ & $43.9 \pm 11.8^{* * \dagger}$ \\
\hline VLDL-C (mg/dL) & $17.1 \pm 24.2$ & $29.1 \pm 14.4^{*}$ & $39.6 \pm 22.9^{* * \dagger}$ \\
\hline Non-HDL-C (mg/dL) & $121.14 \pm 15.9$ & $147.8 \pm 44.9^{*}$ & $162.7 \pm 47.7^{* \dagger}$ \\
\hline TC/HDL-C & $3.3 \pm 0.6$ & $4.4 \pm 1.2^{*}$ & $4.5 \pm 1.2^{* *}$ \\
\hline
\end{tabular}

$B M I$ body mass index, SBP systolic blood pressure, DBP diastolic blood pressure, HbA1c hemoglobin A1C, TC total cholesterol, LDL-C low density lipoprotein cholesterol, $H D L-C$ high density lipoprotein cholesterol, VLDL-C very low density lipoprotein cholesterol

* Significant $p$ in comparison between controls and T2DM

** Significant $p$ in comparison between controls and T2DM + CVD

+ Significant $p$ in comparison between T2DM and T2DM + CVD

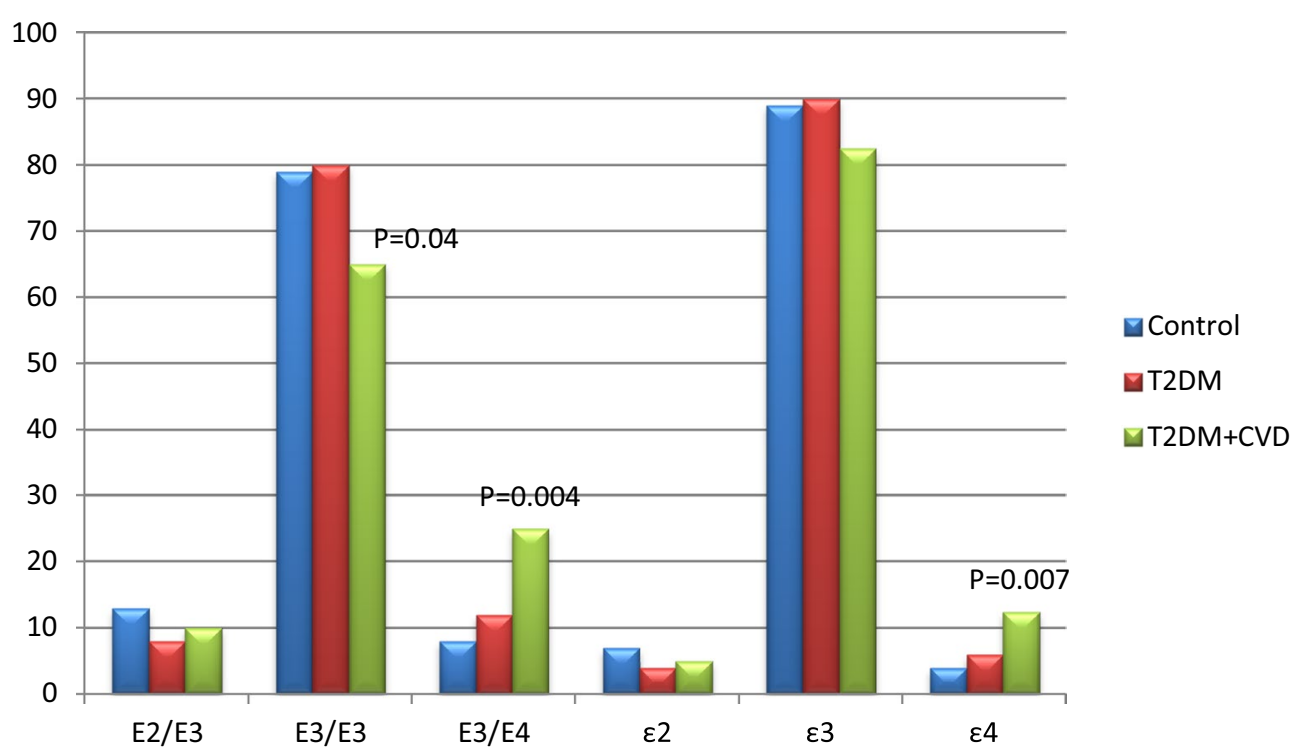

Fig. 1 Genotypes distribution and alleles'frequency of ApoE gene polymorphism in patients and controls 


\section{Association of apoE gene polymorphism with T2DM and CVD}

Univariate analysis to study the association of different genotypes and alleles with the risk of T2DM and CVD as compared to healthy controls showed that E3/E4 genotype associated with 3.6-fold increased risk to develop CVD $(\mathrm{P}=0.004)$ and $\varepsilon 4$ allele associated with 3.2-fold increased CVD risk $(\mathrm{p}=0.007)$. Although, E3/E4 genotype increased the risk for T2DM by 1.5 times, it was of no statistical significance ( $\mathrm{p}=0.41$ ) (Fig. 2).

Association studies for the CVD risk in T2DM patients revealed that diabetic patient who carried E3/
E4 genotype were at 2.4-fold increased risk to develop CVD ( $\mathrm{P}=0.02)$, while $\varepsilon 4$ allele carriers were at 2.23 -fold increased risk ( $\mathrm{P}=0.02$ ) (Fig. 3).

Multivariate logistic regression analysis after adjustment for other established risk factors: age, male gender, BMI, smoking status and physical activity, showed that E3/E4 genotype was an independent risk factor for CVD $(\mathrm{p}=0.009)$ but not for T2DM $(\mathrm{p}=0.28)$. Allele $\varepsilon 4$ was an independent risk factor for both T2DM $(\mathrm{p}=0.04)$ and CVD ( $\mathrm{p}=0.018)$ and increased the risk of CVD in T2DM patients by 5.9 folds $(\mathrm{p}=0.019)$. As regards other covariates, age, BMI, male gender and physical

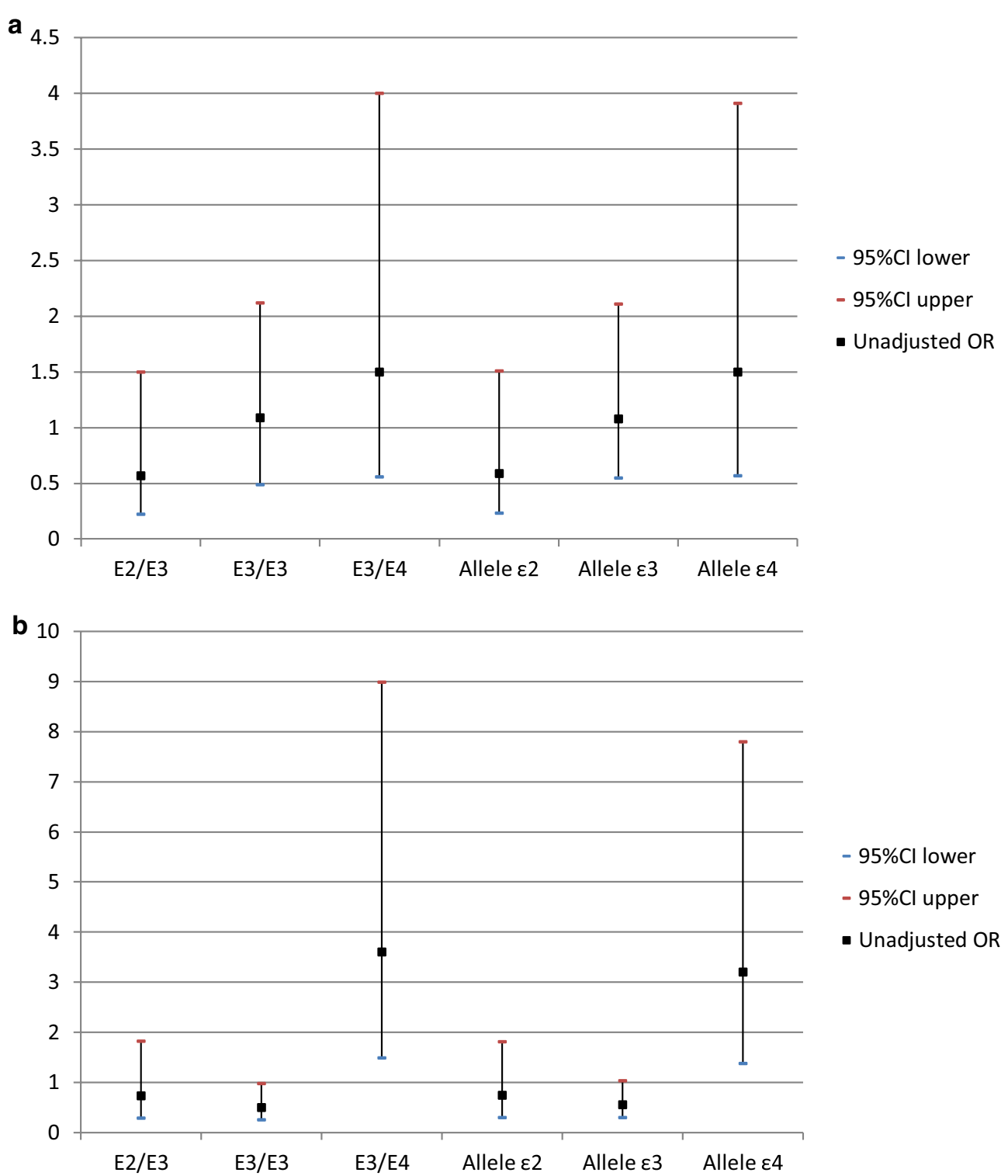

Fig. 2 Association of ApoE gene polymorphism with the risk of T2DM (a), CVD (b) 


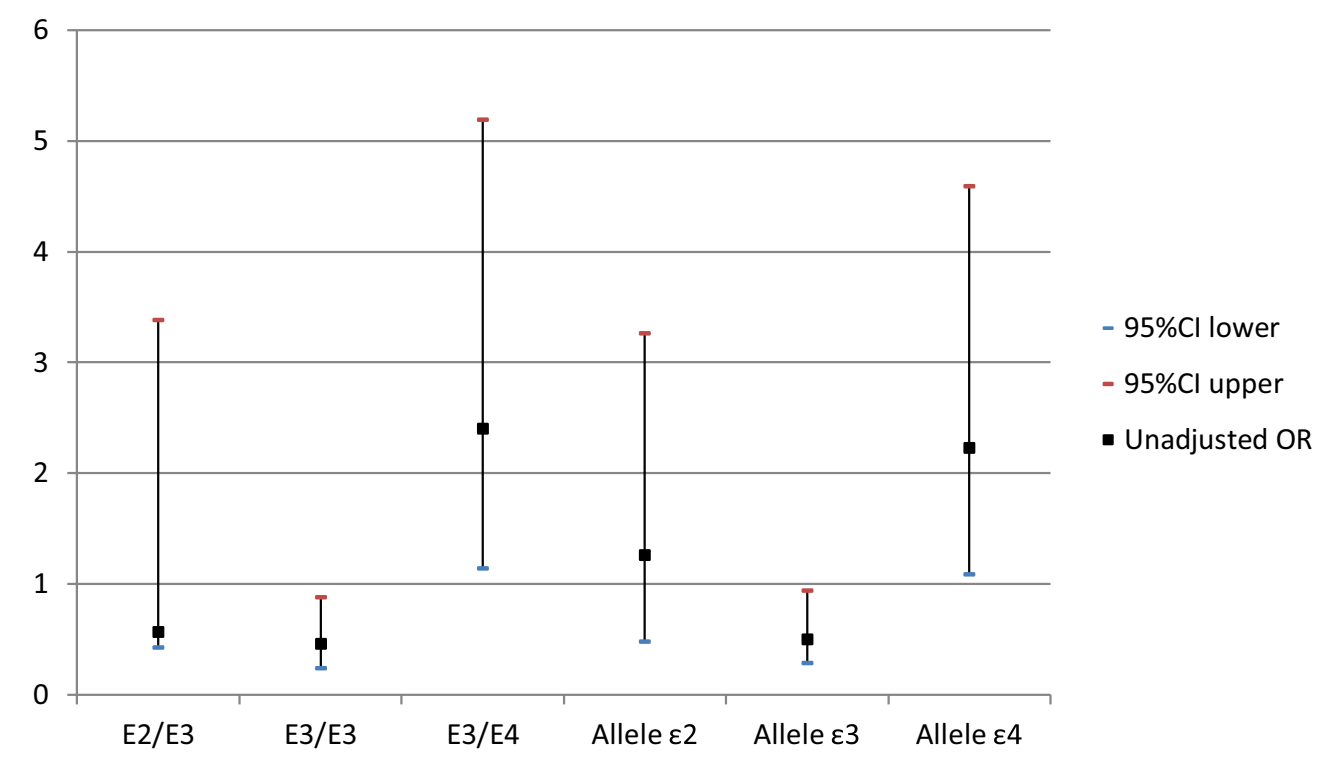

Fig. 3 Associations of apoE gene polymorphism with the risk of CVD in T2DM patients

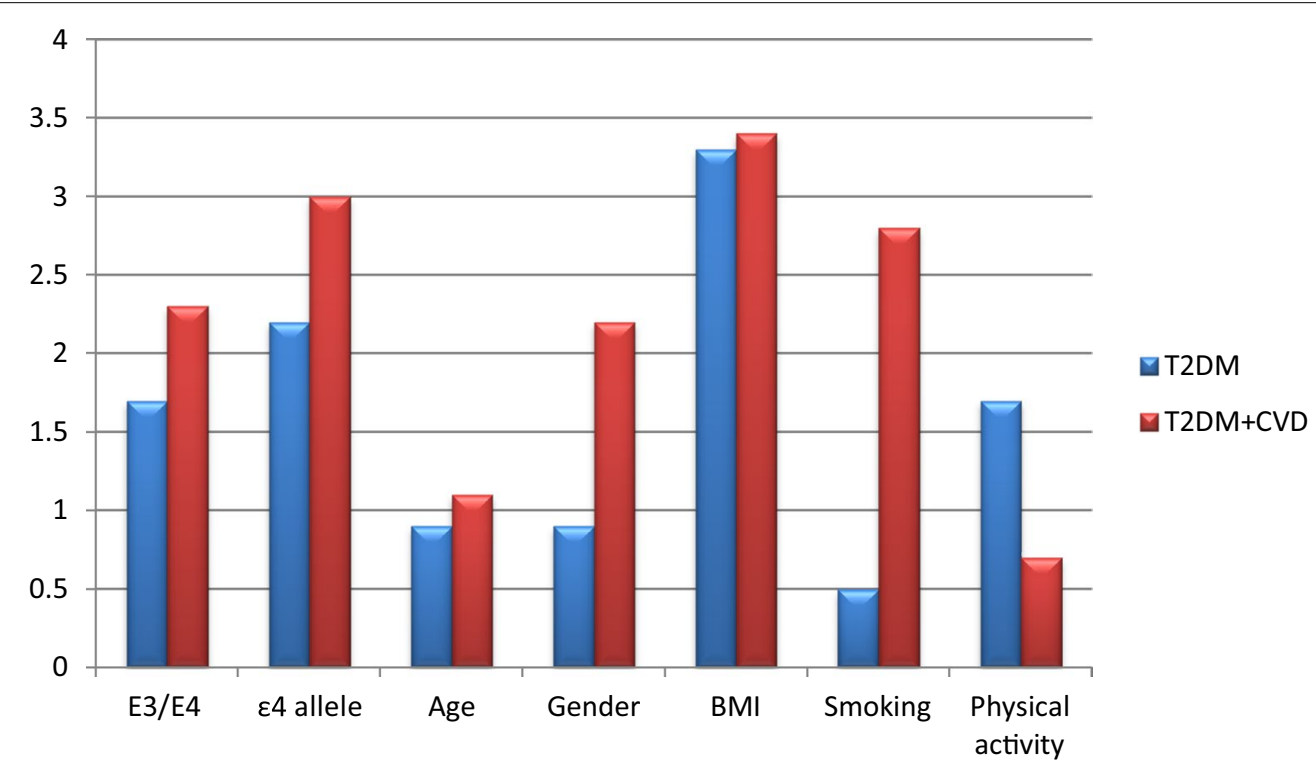

Fig. 4 Adjusted odds ratio (OR) of the multivariate logistic regression analysis for T2DM and CVD risk

activity were independent risk factors for CVD, while BMI was the only independent risk factor for T2DM (Fig. 4). For CVD risk in T2DM patients, age, male gender, BMI, smoking status and physical activity were the independent risk factors. Diabetic smokers were 17.5 times more-at risk to develop CVD than non- smokers $(\mathrm{p}=0.013)$ (Fig. 5).

\section{ApoE genotypes and plasma lipids profile}

By comparing the plasma lipid profile parameters in the E4-bearing genotype in our study i.e. E3/E4 with E3/E3 genotype as a reference, we found that $\mathrm{E} 3 / \mathrm{E} 4$ genotype associated with significantly higher levels of TC and non HDL-C in all groups and significantly higher levels of LDL-C in both T2DM and CVD patients. Though, E3/E4 genotype carriers 


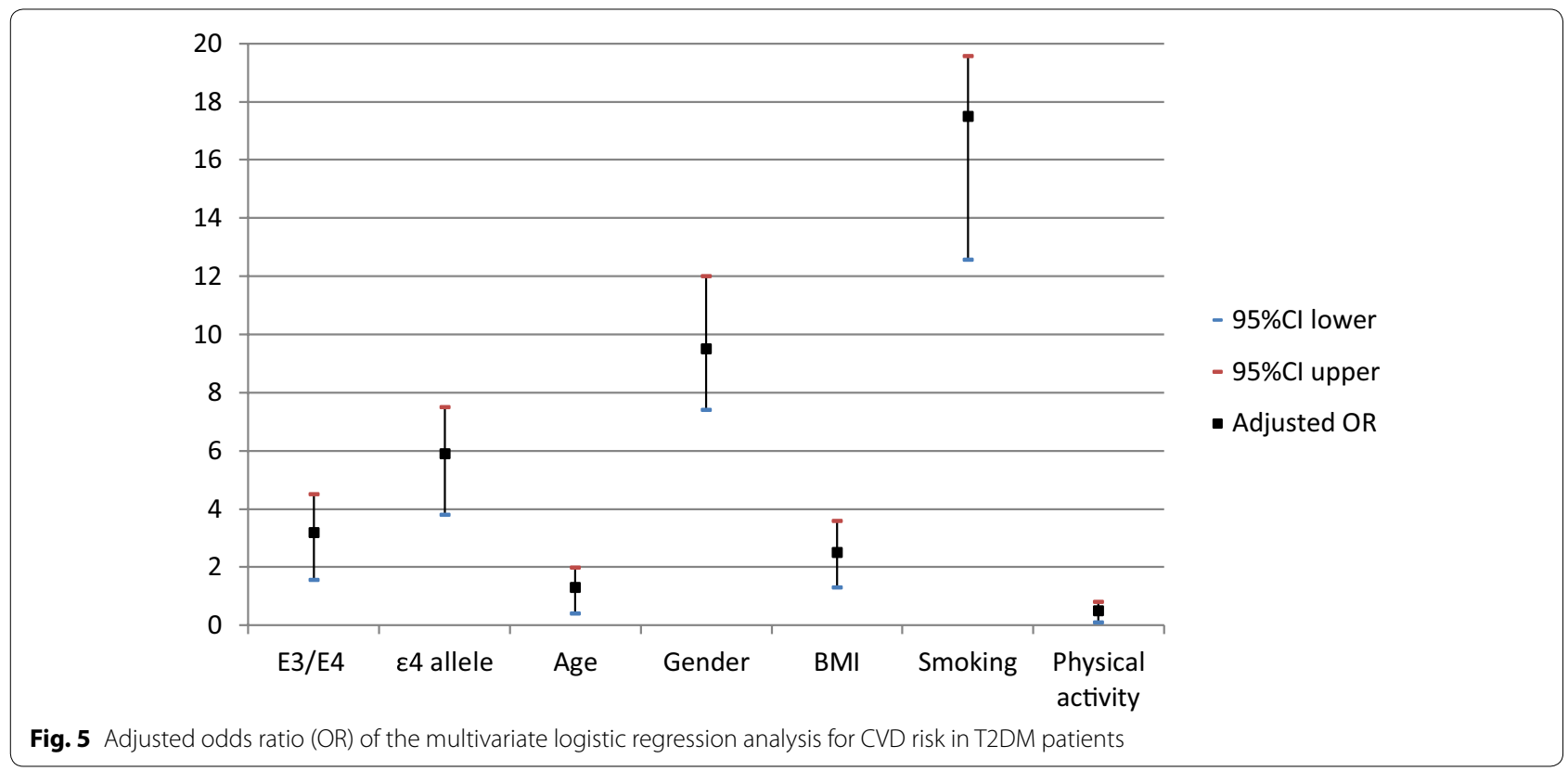

Table 2 Lipid profile parameters in apoE E3/E3 vs. E3/E4 genotypes

\begin{tabular}{|c|c|c|c|c|c|c|}
\hline \multirow{2}{*}{$\begin{array}{l}\text { Parameter } \\
\text { (mg/dl) }\end{array}$} & \multicolumn{2}{|l|}{ Control } & \multicolumn{2}{|l|}{ T2DM } & \multicolumn{2}{|l|}{ T2DM + CVD } \\
\hline & E3/E3 $(n=66)$ & E3/E4 $(n=7)$ & E3/E3 $(n=80)$ & E3/E4 $(n=12)$ & E3/E3 $(n=65)$ & E3/E4 $(n=25)$ \\
\hline TC & $171.24 \pm 25.15$ & $189.42 \pm 8.52^{* *}$ & $191.47 \pm 51.06$ & $223.30 \pm 22.80^{* *}$ & $204.55 \pm 42.35$ & $221.56 \pm 70.37^{*}$ \\
\hline TG & $114.99 \pm 32.08$ & $121.71 \pm 31.19$ & $153.78 \pm 74.98$ & $145.92 \pm 65.05$ & $159.72 \pm 61.47$ & $149.08 \pm 79.28$ \\
\hline HDL-C & $53.14 \pm 10.97$ & $50.85 \pm 9.24$ & $44 \pm 12.52$ & $42.38 \pm 11.08$ & $50.52 \pm 10.85$ & $48.86 \pm 13.49$ \\
\hline LDL-C & $109.06 \pm 20.40$ & $96.28 \pm 4.85$ & $116.72 \pm 40.17$ & $151.76 \pm 18.85^{* *}$ & $121.67 \pm 43.16$ & $135 \pm 61.85^{*}$ \\
\hline VLDL-C & $20 \pm 9.6$ & $21 \pm 11.8$ & $29.75 \pm 14.95$ & $31.15 \pm 12.61$ & $32.35 \pm 12.16$ & $35.7 \pm 23.15$ \\
\hline Non-HDL-C & $118 \pm 19.4$ & $139 \pm 13^{* *}$ & $147.47 \pm 46.27$ & $180.92 \pm 23.76^{* *}$ & $154.03 \pm 41.29$ & $170.7 \pm 61.77^{*}$ \\
\hline
\end{tabular}

Data presented as mean \pm SD

* p value $<0.05$

** $\mathrm{p}$ value $<0.01$

have higher levels of VLDL-C and lower levels of HDL-C, yet the differences were not significant (Table 2).

\section{Discussion}

ApoE is a 299 -amino acids plasma glycoprotein which acts as a high affinity ligand for several hepatic lipoprotein receptors such as LDL-R and LDL-related protein (LRP1) and is involved in several lipoproteins metabolism, transport and digestion [18]. Dyslipidemia or dyslipoproteinemia might strongly contribute in aggravating the micro- and macro-vascular complications and the related accelerated atherosclerosis in diabetic patients [7] and recently has been suggested to be associated with both T2DM and CAD [14]. Since, different apoE isoforms associate with significant variation in lipid profiles [19], the coding apoE gene is a candidate for CVD and/or diabetes. In this work, we studied the association of apoE gene polymorphism with T2DM and CVD and its effect on plasma lipid parameters.

\section{ApoE gene polymorphism and risk of diabetes and CVD}

To our knowledge this is the first study to investigate apoE gene polymorphism in T2DM with and without CVD in our population, E3/E3 was the most common genotype. Significant higher frequencies of E3/E4 genotype and $\varepsilon 4$ allele were observed among our CVD patients. Individuals who carried E3/E4 genotype were at 3.6- fold higher risk to develop CVD while $\varepsilon 4$ allele carriers were at 3.2-fold higher risk. In diabetic patients, E3/E4 genotype and $\varepsilon 4$ allele increased the CVD risk by 2.4- and 2.23-folds, respectively. Multivariate regression analysis identified E3/E4 genotype as an independent risk 
factor for CVD, but not for T2DM, while $\varepsilon 4$ allele was an independent risk factor for both T2DM and CVD and associated with 5.9-fold higher risk of CVD in T2DM patients.

Results from previous studies suggest that apoE $\varepsilon 4$ allele has a variable significance in terms of predicting the risk of vascular events in different populations. In Finnish population, apoE genotypes were found to modulate the risk of coronary heart disease (CHD) and atherosclerotic vascular disease in non-insulin dependent diabetes mellitus (NIDDM) [20, 21]. Genotypes E4/ $\mathrm{E} 4$ and $\mathrm{E} 3 / \mathrm{E} 4$ associated with increased risk for CHD in NIDDM patients and the prevalence of CHD disease among diabetic patients with genotypes E4/E4 or E3/ E4 was 81 vs. $58 \%$ among patients with genotype E3/ E3, and $53 \%$ among those with genotypes E2/E2 or E3/ E3 [20]. Also, E4-bearing genotypes associated with increased risk for macro and micro vascular complications in NIDDM patients both in men and women, in contrast to E2 phenotype which somehow protected from macroangiopathy and associated with lower plasma TC and LDL-C concentrations and lower plasma lipoprotein (a) levels [21]. In contrast, apo E polymorphism, notably, the $\varepsilon 4$ allele was not found to influence the risk for cardiovascular disease in Italian diabetic patients and no significant differences among different genotypes were identified [22]. However, in another Italian study, apoE $\varepsilon 4$ allele was reported as a risk factor for CAD and has been associated with low apoE concentrations [23]. In Greek patients with CAD, there was no significant association between $\varepsilon 4$ allele and risk for CAD or myocardial infarction (MI), though a negative association of $\varepsilon 2$ allele with $\mathrm{Ml}$ was observed [24]. Also, $\varepsilon 4$ allele was not associated with an increased risk for CVD or ischemic vascular event (IVE) among Greek patients with CVD [25].

Meanwhile, significant association between ApoE polymorphism and CAD has been reported in several ethnic groups [12, 14, 26-34]. In Chinese study, apoE $\varepsilon 4$ allele was reported to be associated with the increased risk of CAD in T2DM. Diabetic patients who carried E3/E4 or E4/E4 genotypes had higher concentrations of serum TC, LDL-C and lipoprotein (a) than patients with $\mathrm{E} 2 / \mathrm{E} 2$ or E3/E2 genotypes, they also had the highest mortality rate (50 \%) during 3-10 years follow-up period [12].

In Thai population, Apo $\varepsilon 4$ allele has been reported as an independent risk factor for the development of both T2DM and CAD [14]. After adjusting for other risk factors, E3/E4 carriers showed 2.52-fold higher risk for CAD in T2DM patients. Moreover, allele $\varepsilon 4$-bearing genotypes increased the risk of CAD by 2.32 folds and the risk of T2DM by 2.04 folds when compared to controls and the risk increased when combined with smoking and/or obesity confirming that development and progression of diabetes and CAD are multifactorial and no single factor can give a satisfactory explanation regarding the disease development [14].

In a recent meta-analysis evaluating the association of apoE gene polymorphism with atherosclerosis risk including subgroup analysis, the overall analysis and subgroup analysis based on ethnicities showed no significant association between apoE polymorphism and risk of atherosclerosis. However, subgroup analysis based on clinical phenotypes of atherosclerosis (clinical and subclinical atherosclerosis) showed that $\varepsilon 4$ allele associated with incidence of clinical atherosclerosis [35].

In our study, age, BMI, male gender and physical activity were independent risk factors for CVD, while BMI was the only independent risk for T2DM. Diabetic smokers were 17.5 times more-at risk to develop CVD than non-smokers. Recently, smoking and obesity have been reported to be the two major risk factors that can promote the development of T2DM and CAD or both [14] which has been attributed to the enhanced oxidative stress that results in decreased insulin secretion and decreased uptake by the muscle cells [36]. Oxidative stress also increases vascular inflammation and involved in the development of CVD with or without combination of diabetes [37].

\section{Oxidative stress and vascular complications in diabetes}

Hyperglycemia-induced oxidative stress in diabetic patients induces endothelial dysfunction which plays a central role in the pathogenesis of vascular diseases and may also increase pro-inflammatory and pro-coagulant factors expression [38]. Lower plasma levels of extracellular superoxide dismutase (EC-SOD), a major antioxidant enzyme, and higher plasma levels of advanced oxidation protein products (AOPP), markers of oxidative stress, have been detected and associated with myocardial infarction in diabetic patients [39].

Also, the anti-atherogenic properties of HDL might be affected by hyperglycemia. Glycated HDL has a reduced ability to protect against oxidation and in vitro studies showed that glycation can both inactivate PON1 (an enzyme that accounts for most of the antioxidant effect of HDL to prevent oxidation of LDL) and increase lipid peroxidation in HDL [40, 41]. Reduced PON-1 activity and concentration in studies of healthy subjects with elevated fasting glucose levels [42] and increased insulin resistance [43] support these in vitro data.

In a previous study on serum advanced glycation end products (AGEs) and its association with oxidative stress and PON-1 activity in T2DM patients, lower enzyme activity has been associated with vascular complications and AGEs showed a significant negative correlation 
with enzyme activity [44]. Apolipoprotein A-1 (apoAI) is the major protein component of HDL that plays a major role in cholesterol homeostasis and exerts antiinflammatory, antioxidant, and anti-atherogenic properties by stabilizing PON-1 enzyme [45]. In a recent study, glycated apoA-I has been reported to be associated with decreased activities of serum and HDL-associated PON1 and PON3 as well as the presence and severity of CAD in T2DM patients [46].

Recently, an interaction between the $\gamma$-glutamyltransferase- 1 (GGT1) genotype and low serum levels of HDL-C has been identified in diabetic micro and macro angiopathy particularly among the $\mathrm{G}$ allele carriers, a variant that was associated with higher GGT serum levels. Increased pro-oxidant effect of GGT by increased LDL-associated GGT and GGT-mediated LDL-oxidation, together with coexisting low HDL-C, was suggested to be the mechanism linking GGT to the cardiovascular events [47].

\section{Effect of apoE genotype on plasma lipids}

Our results showed that E3/E4 genotype associated with higher levels of TC and non HDL-C in all studied subjects, and with higher levels LDL-C in both T2DM and CVD patients highlighting the significance of increased LDL-C levels in T2DM and CVD development, in contrast to the previous report that non-HDL-C level is a strong predictor of CVD risk in T2DM and is particularly indicative of coronary events [48].

Results from previous studies regarding the relation between the apoE genotype and plasma lipids profile are inconsistent among different ethnic populations. In Indians, E3/E4 genotype was associated with lower HDL-C and higher LDL-C concentrations in CAD patients [49] and with higher TG levels in T2DM patients [50]. In Thai population, $\varepsilon 4$ allele-diabetic carriers showed a significantly higher VLDL-C, TG and lower HDL-C levels compared to E3/E3 genotype carriers [14]. In a recent study on Kashmiri population, $\varepsilon 4$ allele associated with significantly higher levels of LDL and TC in CAD patients [34]. ApoE $\varepsilon 4$ allele associated with increased LDL-C in Tunisian men with T2DM [32] and with higher LDL-C and lower HDL-C levels in Spanish women with T2DM [51] suggesting that gender might affect the impact of apoE gene polymorphism on lipid parameters [14].

\section{Conclusion}

Our study indicates that apoE gene polymorphisms associate with CVD and identifies apoE $\varepsilon 4$ allele as an independent risk factor for both T2DM and CVD. Different apoE genotypes associate with significant variation in plasma lipids profile. Multiple risk factors interact and play a role in the development of T2DM and/or CVD. Further genetic studies to add information beyond the traditional cardiovascular risk factors in T2DM patients and to identify risk genotypes will help in early prediction and identification of at risk patients.

\section{Abbreviations}

T2DM: type 2 diabetes mellitus; IDF: International Diabetes Federation; NCDs: non-communicable diseases; IGT: impaired glucose tolerance; CVD: cardiovascular disease; CAD: coronary artery disease; ApoE: apolipoprotein E; BMI: body-mass index; SBP: systolic blood pressure; DBP: diastolic blood pressure; FPG: fasting plasma glucose; TC: total cholesterol; TG: triglycerides; LDL: low-density lipoprotein; HDL: high-density lipoprotein; VLDL: very low density lipoprotein; HbA1c: glycosylated hemoglobin; CHD: coronary heart disease; IHD: ischemic heart disease; HPLC: high-performance liquid chromatographic; PCR: polymerase chain reaction; SNP: single nucleotide polymorphism; LDL-R: lipoprotein receptors; LRP1: LDL-related protein; CHD: coronary heart disease; NIDDM: non-insulin dependent diabetes mellitus; MI: myocardial infarction; IVE: ischemic vascular event.

\section{Authors' contributions}

DE made the study design. DE and HR participated in selection of patients. DE made the genetic analysis, laboratory investigations and interpretation of data. AM made the statistical analysis. DE wrote the drafting manuscript. All authors read and approved the final manuscript.

\section{Author details}

${ }^{1}$ Medical Research Division, Department of Clinical and Chemical Pathology, National Research Centre, Al-Bohouth Street, Cairo 12311, Egypt. ${ }^{2}$ Medical Research Division, Department of Internal Medicine, National Research Centre, Cairo, Egypt. ${ }^{3}$ Department of Environmental and Occupational Medicine, National Research Centre, Cairo, Egypt.

\section{Acknowledgements}

This work was funded by the National Research Centre (Research Project no. 10010309).

\section{Competing interests}

The authors declare that they have no competing interests.

Received: 30 September 2015 Accepted: 4 January 2016 Published online: 22 January 2016

\section{References}

1. King H, Aubert RE, Herman WH. Global burden of diabetes, 1995-2025: prevalence, numerical estimates, and projections. Diabetes Care. 1998;21:1414-31.

2. International Diabetes Federation (IDF). Diabetes Atlas, 2nd edn. Brussels: International Diabetes Federation. 2003.

3. International Diabetes Federation (IDF). Diabetes Atlas, 5th edn. Brussels: International Diabetes Federation. 2013, update.

4. Lorber D. Importance of cardiovascular disease risk management in patients with type 2 diabetes mellitus. Diabetes Metab Syndr Obes. 2014;7:169-83.

5. http://www.idf.org/webdata/docs/background_cairo.pdf. Accessed 15 Sep 2015.

6. Horejsí B, Ceska R. Apolipoproteins and atherosclerosis. Apolipoprotein E and apolipoprotein (a) as candidate genes of premature development of atherosclerosis. Physiol Res. 2000;49(Suppl 1):S63-9.

7. Jenkins AJ, Rowley KG, Lyons TJ, Best JD, Hill MA, Klein RL. Lipoproteins and diabetic microvascular complications. Curr Pharm Des. 2004;10:3395-418.

8. Ferreira CN, Carvalho MG, Fernandes AP, Lima LM, Loures-Valle AA, Dantas J, Janka Z, Palotás A. Sousa MO. Comparative study of apolipoprotein-E polymorphism and plasma lipid levels in dyslipidemic and symptomatic subjects, and their implication in cardio/cerebro-vascular disorders Neurochem Int. 2010;56(1):177-82.

9. Grundy SM. Drug therapy of the metabolic syndrome: minimizing the emerging crisis in polypharmacy. Nat Rev Drug Discov. 2006;5:295-309. 
10. Singh PP, Singh M, Mastana SS. APOE distribution in world populations with new data from India and the UK. Ann Hum Biol. 2006;33:279-308.

11. Eichner JE, Dunn ST, Perveen G, Thompson DM, Stewart KE, Stroehla BC. Apolipoprotein E polymorphism and cardiovascular disease: a HuGE review. Am J Epidemiol. 2002;155:487-95.

12. Guang-da X, You-ying L, Zhi-song C, Yu-sheng H, Xiang-jiu Y. Apolipoprotein $\varepsilon 4$ allele is predictor of coronary artery disease death in elderly patients with type 2 diabetes mellitus. Atherosclerosis. 2004;175:77-81.

13. Knouff C, Hinsdale ME, Mezdour H, Altenburg MK, Watanabe M, Quarfordt $\mathrm{SH}$, Sullivan PM, Maeda N. Apo E structure determines VLDL clearance and atherosclerosis risk in mice. J Clin Invest. 1999;103:1579-86.

14. Chaudhary R, Likidlilid A, Thavatchai Peerapatdit T, Damras Tresukosol D, Srisuma S, Ratanamaneechat S, Sriratanasathavorn C. Apolipoprotein E gene polymorphism: effects on plasma lipids and risk of type 2 diabetes and coronary artery disease. Cardiovasc Diabetol. 2012;11:36.

15. Jellinger PS, Dickey RA, Ganda OP, Mehta AE, Nguyen TT, Rodbard HW, Seibel JA, Shepherd MD, Smith DA, AACE Lipid Guidelines Committee. The American Association of Clinical Endocrinologists medical guidelines for clinical practice for the diagnosis and treatment of dyslipidemia and prevention of atherogenesis. Endocr Pract. 2000;6(2):162-213.

16. American Diabetes Association. Diagnosis and classification of diabetes mellitus. Diabetes Care. 2014;37(Suppl. 1):S81-90.

17. Hermans MP, Sacks FM, Ahn SA, Rousseau MF. Non-HDL-cholesterol as valid surrogate to apolipoprotein B100 measurement in diabetes: discriminant ratio and unbiased equivalence. Cardiovasc Diabetol. 2011;10:20.

18. Mahley RW, Rall SC. Apolipoprotein E: far more than a lipid transport protein. Annu Rev Genomics Hum Genet. 2000;1:507-37.

19. Mendes-Lana A, Pena GG, Freitas SN, Lima AA, Nicolato RL, NascimentoNeto RM, Machado-Coelho GL, Freitas RN. Apolipoprotein E polymorphism in Brazilian dyslipidemic individuals: Ouro Preto study. Braz J Med Biol Res. 2007:40(1):49-56.

20. Laakso M, Kesäniemi A, Kervinen K, Jauhiainen M, Pyörälä K. Relation of coronary heart disease and apolipoprotein E phenotype in patients with non-insulin dependent diabetes. BMJ. 1991;303(6811):1159-62.

21. Ukkola O, Kervinen K, Salmela PI, von Dickhoff K, Laakso M, Kesäniemi YA. Apolipoprotein E phenotype is related to macro- and microangiopathy in patients with non-insulin-dependent diabetes mellitus. Atherosclerosis. 1993;101(1):9-15

22. Boemi M, Sirolla C, Amadio L, Fumelli P, Pometta D, James RW. Apolipoprotein E polymorphism as a risk factor for vascular disease in diabetic patients. Diabetes Care. 1995;18(4):504-8.

23. Corbo RM, Vilardo T, Ruggeri M, Gemma AT, Scacchi R. Apolipoprotein E genotype and plasma levels in coronary artery disease. A case-control study in the Italian population. Clin Biochem. 1999;32:217-22.

24. Kolovou G, Yiannakouris N, Hatzivassiliou M, Malakos J, Daskalova D, Hatzigeorgiou G, Cariolou MA, Cokkinos DV. Association of apolipoprotein E polymorphism with myocardial infarction in Greek patients with coronary artery disease. Curr Med Res Opin. 2002;18(3):118-24.

25. Kolovou GD, Daskalova DCh, Hatzivassiliou M, Yiannakouris N, Pilatis ND, Elisaf M, Mikhailidis DP, Cariolou MA, Cokkinos DV. The epsilon 2 and 4 alleles of apolipoprotein $\mathrm{E}$ and ischemic vascular events in the Greek population-implications for the interpretation of similar studies. Angiology. 2003;54(1):51-8.

26. Vaisi-Raygani A, Rahimi Z, Nomani H, Tavilani H, Pourmotabbed T. The presence of apolipoprotein epsilon4 and epsilon2 alleles augments the risk of coronary artery disease in type 2 diabetic patients. Clin Biochem. 2007;40(15):1150-6.

27. Attila G, Acarturk E, Eskandari G, Akpinar O, Tuli A, Kanadas IM, Kayrin L. Effects of apolipoprotein E genotypes and other risk factors on the development of coronary artery disease in Southern Turkey. Clin Chim Acta. 2001;312(1-2):191-6.

28. Kumar P, Luthra K, Dwivedi M, BehI VK, Pandey RM, Misra A. Apolipoprotein $\mathrm{E}$ gene polymorphisms in patients with premature myocardial infarction: a case controlled study in Asian Indians in North India. Ann Clin Biochem. 2003;40:382-7.

29. Eichner JE, Kuller LH, Orchard TJ, Grandits GA, McCallum LM, Ferrell $\mathrm{RE}$, Neaton JD. Relation of apolipoprotein E phenotype to myocardial infarction and mortality from coronary artery disease. Am J Cardiol. 1993;71:160-5.
30. Van Bockxmeer FM, Mamotte CD. Apolipoprotein epsilon4 homozygosity in young men with coronary heart disease. Lancet. 1992;340:879-80.

31. Yan S, Zhou X, Lin Q, Song Y. Association of polymorphism of apolipoprotein E gene with coronary heart disease in Han Chinese. Chin Med J (Engl). 1999;112:224-7.

32. Chaaba R, Attia N, Hammami S, Smaoui M, Ben Hamda K, Mahjoub S, Hammami M. Association between apolipoprotein E polymorphism, lipids, and coronary artery disease in Tunisian type 2 diabetes. J Clin Lipidol. 2008;2:360-4.

33. Halim EF, Reda AA, Hendi AA, Zaki SA, Essa ES, Khalifa AS. Apolipoprotein $\mathrm{E}$ gene variants as a risk factor for coronary artery disease in type 2 diabetic Egyptian patients. Egypt J Immunol. 2012;19(1):1-10.

34. Afroze D, Yousuf A, Tramboo NA, Shah ZA, Ahmad A. ApoE gene polymorphism and its relationship with coronary artery disease in ethnic Kashmiri population. Clin Exp Med. 2015; 1-6.

35. Zhu H, Xue H, Wang HT, Ma YM, Liu J, Chen YD. The association of apolipoprotein E (APOE) gene polymorphisms with atherosclerosis susceptibility: a meta-analysis. Minerva Cardioangiol. 2015 [Epub ahead of print].

36. Evans JL, Goldfine ID, Maddux BA, Grodsky GM. Oxidative stress and stress activated signaling pathways: a unifying hypothesis of type 2 diabetes. Endocr Rev. 2002;23:599-622.

37. Tosukhowong P, Sangwatanaroj S, Jatuporn S, Prapunwattana P, Saengsiri A, Rattanapruks S, Srimahachota S, Udayachalerm W, Tangkijvanich P. The correlation between markers of oxidative stress and risk factors of coronary artery disease in Thai patients. Clin Hemorheol Microcirc. 2003;29:321-9.

38. Fiorentino TV, Prioletta A, Zuo P, Folli F. Hyperglycemia-induced oxidative stress and its role in diabetes mellitus related cardiovascular diseases. Curr Pharm Des. 2013;19(32):5695-703.

39. Mohammedi K, Bellili-Muñoz N, Marklund SL, Driss F, Le Nagard H, Patente TA, Fumeron F, Roussel R, Hadjadj S, Marre M, Velho G. Plasma extracellular superoxide dismutase concentration, allelic variations in the SOD3 gene and risk of myocardial infarction and all-cause mortality in people with type 1 and type 2 diabetes. Cardiovasc Diabetol. 2015;14:845.

40. Hedrick CC, Thorpe SR, Fu MX. Glycation impairs high-density lipoprotein function. Diabetologia. 2000;43:312-20.

41. Ferretti G, Bacchetti T, Marchionni C, Caldarelli L, Curatola G. Effect of glycation of high density lipoproteins on their physiochemical properties and on paraoxonase activity. Acta Diabetol. 2001;38:163-9.

42. Leviev I, Kalix B, Brulhart-Meynet MC, James RW. The paraoxonase PON1 promoter polymorphism C $(-107) \mathrm{T}$ is associated with increased serum glucose concentrations in non-diabetic patients. Diabetologia. 2001;44:1177-83.

43. Senti M, Tomas M, Fito M. Anti oxidant paraoxonase-1 activity in the metabolic syndrome. J Clin Endocrinol Metab. 2003;88:5422-6.

44. Bansal S, Chawla D, Siddarth M, Banerjee BD, Madhu SV, Tripathi AK. A study on serum advanced glycation end products and its association with oxidative stress and paraoxonase activity in type 2 diabetic patients with vascular complications. Clin Biochem. 2013;46(1-2):109-14.

45. Getz GS, Wool GD, Reardon CA. Biological properties of apolipoprotein A-I mimetic peptides. Curr Atheroscler Rep. 2010;12(2):96-104.

46. Shen Y, Ding FH, Sun J, Pu LJ, Zhang RY, Zhang Q, Chen QJ, Shen WF, Lu L. Association of elevated apoA-I glycation and reduced $\mathrm{HDL}$-associated paraoxonase 1, 3 activity, and their interaction with angiographic severity of coronary artery disease in patients with type 2 diabetes mellitus. Cardiovasc Diabetol. 2015;14:52.

47. Jinnouchi H, Morita K, Tanaka T, Kajiwara A, Kawata Y, Oniki K, Saruwatari J, Nakagawa K, Otake K, Ogata Y, Yoshida A, Hokimoto S, Ogawa H. Interactive effects of a common $\gamma$-glutamyltransferase- 1 variant and low high-density lipoprotein-cholesterol on diabetic macro- and microangiopathy. Cardiovasc Diabetol. 2015;14:49.

48. Lu W, Resnick HE, Jablonski KA, Jones KL, Jain AK, Howard WJ, Robbins DC, Howard BV. Non-HDL cholesterol as a predictor of cardiovascular disease in type 2 diabetes: the strong heart study. Diabetes Care. 2003;26(1):16-23.

49. Singh PP, Singh M, Bhatnagar DP, Kaur TP, Gaur SK. Apolipoprotein E polymorphism and its relation to plasma lipids in coronary heart disease. Indian J Med Sci. 2008;62:105-12. 
50. Inamdar PA, Kelkar SM, Devasagayam TP, Bapat MM. Apolipoprotein E polymorphism in non-insulin-dependent diabetics of Mumbai, India and its effect on plasma lipids and lipoproteins. Diabetes Res Clin Pract. 2000;47:217-23
51. Gomez-Coronado D, Alvarez JJ, Entrala A, Olmos JM, Herrera E, Lasuncion MA. Apolipoprotein E polymorphism in men and women from a Spanish population: allele frequencies and influence on plasma lipids and apolipoproteins. Atherosclerosis. 1999;147:167-76.
Submit your next manuscript to BioMed Central and we will help you at every step:

- We accept pre-submission inquiries

- Our selector tool helps you to find the most relevant journal

- We provide round the clock customer support

- Convenient online submission

- Thorough peer review

- Inclusion in PubMed and all major indexing services

- Maximum visibility for your research

Submit your manuscript at www.biomedcentral.com/submit
() Biomed Central 